\title{
Níveis de treonina digestível em dietas para codorna japonesa em postura ${ }^{1}$
}

\section{Regina Tie Umigi ${ }^{2}$, Sergio Luiz de Toledo Barreto ${ }^{3}$, Juarez Lopes Donzele ${ }^{3}$, Renata de Souza Reis ${ }^{4}$, Mariele Freitas Sousa ${ }^{4}$, Carla Daniela Suguimoto Leite ${ }^{4}$}

\author{
1 Parte da tese de Mestrado da primeira autora. \\ 2 Doutoranda do DZO - UFV - Viçosa - MG. \\ ${ }^{3}$ DZO - UFV - CEP: 36571-000 - Viçosa - MG. \\ ${ }^{4}$ Graduação em Zootecnia - DZO - UFV - Viçosa - MG.
}

RESUMO - O experimento foi conduzido para estimar o nível de treonina digestível para codornas japonesas em postura, durante 63 dias. Quatrocentas codornas, com idade inicial de 57 dias, foram distribuídas em delineamento inteiramente casualizado com cinco tratamentos, oito repetições e 10 aves por unidade experimental. A dieta basal, deficiente em treonina e com 20\% PB, $2.910 \mathrm{kcal}$ EM/kg, foi suplementada com cinco níveis de L-treonina 98\% (0,018; 0,074; 0,128; 0,183 e 0,239\%), correspondendo à relação treonina digestível:lisina digestível de 0,$65 ; 0,70 ; 0,75 ; 0,80$ e 0,85 , respectivamente, para compor os tratamentos experimentais. As características estudadas foram: consumo de ração, consumo de treonina, produção de ovos, produção de ovos comercializáveis, peso do ovo, massa de ovos, conversão alimentar por massa de ovos, conversão alimentar por dúzia de ovos, qualidade dos ovos (gema, albúmen e casca), altura e diâmetro dos ovos e gravidade específica. Observou-se efeito linear dos tratamentos somente sobre o consumo de treonina. Concluiu-se que, para proporcionar os melhores resultados de desempenho e de qualidade de ovos, a codorna japonesa não exige mais que 0,65\% de treonina digestível para um consumo de 149,2 mg de treonina digestível/dia ou um consumo diário de 14,34 mg de treonina digestível/g ovo, correspondendo à relação treonina digestível:lisina digestível de 0,65.

Palavras-chave: aminoácido digestível, Coturnix coturnix japonica, produção de ovos, proteína ideal

\section{Digestible threonine levels in diets for laying Japanese quail}

\begin{abstract}
The experiment was carried out to estimate the level of digestible threonine for laying japanese quail during 63 days. A total of 400 japanese quails, with inicial age of 57 days were allotted to a complete randomized experimental design with five treatments, eight replicates and ten birds per experimental unit. The basal diet, deficient in threonine and with $20 \%$ C, $2,910 \mathrm{kcal} \mathrm{ME} / \mathrm{kg}$, was supplemented with five levels of L-threonine $98 \%(0.018,0.074,0.128,0.183$, and $0.239 \%)$, corresponding to digestible threonine: digestible lysine ratios $0.65,0.70,0.75,0.80$, and 0.85 , respectively, to compose the experimental treatments. The characteristics evaluated were: feed intake, threonine intake, egg production, production of commercial eggs, egg weight, egg mass, feed conversion per egg mass, feed conversion per egg dozen, egg quality (yolk, albumen and shell), egg length and width and specific gravity. Linear effect was only observed in the threonine intake. In conclusion, to provide the best performance results and of the quality of eggs, the Japanese quail does not require more than $0.65 \%$ of digestible threonine for a intake of $149.2 \mathrm{mg}$ of digestible threonine/day or a daily intake of $14.34 \mathrm{mg}$ of digestible threonine/g egg, corresponding to the digestible threonine: digestible lysine ratio of 0.65 .
\end{abstract}

Key Words: Coturnix coturnix japonica, digestible amino acid, egg production, ideal protein

\section{Introdução}

A codorna japonesa (Coturnix coturnix japonica) surgiu no Japão, em 1910, pelo cruzamento entre as codornas européias (Coturnix coturnix coturnix) e espécies selvagens. Maturidade sexual precoce ( 35 a 40 dias), alta taxa de postura (em média 300 ovos/ave/ano), elevada densidade de criação, baixo investimento, rápido retorno do capital investido e elevada vida produtiva são os principais fatores que têm contribuído para sua criação (Albino \& Barreto, 2003).

Na criação de codornas, os estudos em nutrição tornaram-se ainda mais relevantes, pois é justamente sobre o fator alimentação que recai a maior parcela do ônus de produção, direcionados, em grande parte, aos alimentos protéicos da ração. Com a disponibilidade de vários aminoácidos sintéticos no mercado a preços acessíveis, uma das alternativas para a redução dos custos é a incorporação de aminoácidos sintéticos às rações, o que permite 
a formulação de dietas com teores de $\mathrm{PB}$ inferiores àqueles recomendados nas tabelas de exigências nutricionais (Silva et al., 1997).

Em dietas para aves à base de milho e farelo de soja, a treonina é o terceiro aminoácido limitante, precedido dos aminoácidos sulfurosos e da lisina. É exigido para formação da proteína e manutenção do turnover protéico corporal, além de auxiliar na formação do colágeno e da elastina e atuar na produção de anticorpos. A L-treonina pura é 100\% digestível e está disponível comercialmente, oferecendo maior flexibilidade na formulação de dietas. Sua suplementação permite menor inclusão de alimentos protéicos, acarretando menores excreção de nitrogênio e poluição ambiental.

As formulações de dietas para codornas baseiam-se em tabelas de exigências nutricionais de outros países, como o NRC (1994) e o INRA (1999), ou nas extrapolações dos valores nutricionais constantes nas tabelas de exigências de frangos de corte e/ou galinhas poedeiras, o que pode comprometer a produtividade e acarretar prejuízos econômicos (no caso de utilização de níveis, às vezes excessivos, de alguns nutrientes). O próprio NRC (1994) cita que, desde 1984, não foram publicados novos resultados das exigências nutricionais para codornas, comprovando a grande defasagem de informações sobre esta espécie.

Objetivou-se com este trabalho determinar o nível de treonina em dietas para codorna japonesa em postura.

\section{Material e Métodos}

Este experimento foi conduzido no setor de Avicultura do Departamento de Zootecnia da Universidade Federal de Viçosa, no período de abril a junho de 2005, com duração de 63 dias.

Foram utilizadas 400 codornas japonesas fêmeas (Coturnix coturnix japonica) com 57 dias de idade, peso médio de 156,3 g e taxa inicial de postura de 75,5\%.

O experimento foi desenvolvido em delineamento experimental inteiramente casualizado (DIC), constituído por cinco tratamentos (níveis de treonina), com oito repetições e 10 aves por unidade experimental.

As aves foram alojadas em gaiolas de arame galvanizado (100 cm de comprimento x $23 \mathrm{~cm}$ de largura x $20 \mathrm{~cm}$ de altura), dispostas em três andares, montadas em esquema de escada. Cada gaiola foi subdividida em duas repartições iguais $(50 \mathrm{~cm})$, onde foram alojadas dez aves por repartição, totalizando uma área de $115 \mathrm{~cm}^{2} /$ ave. Utilizaram-se comedouro (parte frontal da gaiola) e bebedouro (parte posterior da gaiola), do tipo calha, em chapa metálica gal- vanizada, que percorriam toda a extensão das gaiolas. Sobre o piso de cimento, abaixo das gaiolas, foi colocada uma camada de maravalha para absorver o excesso de umidade das excretas.

As dietas foram formuladas à base de milho, farelo de soja e farelo de glúten de milho. Para atender às exigências nutricionais das codornas, adotaram-se as recomendações preconizadas pelo NRC (1994), exceto para as exigências de metionina + cistina digestíveis e de cálcio, que se basearam nas recomendações de Pinto et al. (2003) e Barreto (2007), respectivamente. Para assegurar a ausência de deficiências, foram acrescentados 4\% nas exigências de cada aminoácido. A composição química e os valores nutricionais dos ingredientes utilizados para a formulação da dieta foram determinados segundo Rostagno et al. (2000). A dieta basal foi suplementada com cinco níveis de L-treonina $98 \%(0,018$; 0,074; 0,$128 ; 0,183$ e 0,239\%), em substituição ao ácido glutâmico, em equivalente protéico correspondente à relação treonina digestível:lisina digestível de 0,$65 ; 0,70 ; 0,75$; 0,80 e 0,85 , de modo que as dietas permanecessem isoprotéicas, isocalóricas e isonitrogênicas. As diferenças entre os equivalentes protéicos de treonina e ácido glutâmico, nos diferentes níveis de treonina, foram compensadas pelo amido (Tabela 1).

A dieta e a água foram fornecidas à vontade durante todo período experimental.

O manejo diário consistiu em recolher e contabilizar os ovos (foi computado diariamente o número de ovos quebrados, trincados, com casca mole e sem casca), fornecer a dieta e limpar os bebedouros e os aparadores de ovos. As temperaturas $\left({ }^{\circ} \mathrm{C}\right)$ e a UR das salas foram monitoradas por meio de termômetros de máxima e de mínima e de bulbo seco e úmido, posicionados em um ponto central entre as fileiras de gaiolas, à altura das aves.

O programa de iluminação iniciou-se aos 40 dias de idade das aves, com fornecimento inicial de 14 horas de luz diária e aumentos semanais de 30 minutos de luz, até atingir 17 horas de luz diária, permanecendo o mesmo esquema até o término do período experimental. Este fornecimento de luz foi controlado por um relógio automático (timer).

As temperaturas máxima e mínima obtidas no período experimental foram de 26,3 e $17^{\circ} \mathrm{C}$, respectivamente, e a umidade relativa do ar dentro do galpão, de $80 \%$.

As variáveis estudadas foram: consumo de ração (g/ave/dia), consumo de treonina (mg/ave/dia), produção de ovos por ave dia (\%), produção de ovos por ave alojada (\%), produção de ovos comercializáveis (\%), peso do ovo (g), massa de ovos (g/ave/dia), conversão alimentar por massa de ovos (kg de ração/kg de ovos), conversão alimentar 
Tabela 1 - Composições percentual e calculada das dietas experimentais

Table 1 - Percentage and calculated composition of the experimental diets

\begin{tabular}{|c|c|c|c|c|c|}
\hline \multirow[t]{2}{*}{$\begin{array}{l}\text { Ingrediente (\%) } \\
\text { Ingredient }\end{array}$} & \multicolumn{5}{|c|}{$\begin{array}{c}\text { Nível de treonina digestível (\%) } \\
\text { Digestible threonine level }\end{array}$} \\
\hline & 0,65 & 0,70 & 0,75 & 0,80 & 0,85 \\
\hline Milho (Corn) & 55,696 & 55,696 & 55,696 & 55,696 & 55,696 \\
\hline Farelo de soja (Soybean meal) & 29,285 & 29,285 & 29,285 & 29,285 & 29,285 \\
\hline Glúten de milho (Corn gluten) (60\%) & 1,071 & 1,071 & 1,071 & 1,071 & 1,071 \\
\hline Óleo vegetal (Vegetable oil) & 2,871 & 2,871 & 2,871 & 2,871 & 2,871 \\
\hline Fosfato bicálcico (Dicalcium phosphate) & 1,611 & 1,611 & 1,611 & 1,611 & 1,611 \\
\hline Calcário (Limestone) & 7,004 & 7,004 & 7,004 & 7,004 & 7,004 \\
\hline Sal (Salt) & 0,285 & 0,285 & 0,285 & 0,285 & 0,285 \\
\hline L-Arg (99\%) & 0,165 & 0,165 & 0,165 & 0,165 & 0,165 \\
\hline L-Glu & 0,599 & 0,533 & 0,458 & 0,383 & 0,304 \\
\hline L-Ile & 0,214 & 0,214 & 0,214 & 0,214 & 0,214 \\
\hline L-lys $\mathrm{HCl}$ (79\%) & 0,140 & 0,140 & 0,140 & 0,140 & 0,140 \\
\hline DL-Met (99\%) & 0,313 & 0,313 & 0,313 & 0,313 & 0,313 \\
\hline L- Thr (98\%) & 0,018 & 0,074 & 0,128 & 0,183 & 0,239 \\
\hline L-Trp $(98 \%)$ & 0,027 & 0,027 & 0,027 & 0,027 & 0,027 \\
\hline $\mathrm{L}-\mathrm{Val}$ & 0,181 & 0,181 & 0,181 & 0,181 & 0,181 \\
\hline Amido (Starch) & 0,250 & 0,260 & 0,281 & 0,301 & 0,324 \\
\hline Cloreto de colina (Choline chloride) (60\%) & 0,100 & 0,100 & 0,100 & 0,100 & 0,100 \\
\hline Surmax $^{1}$ & 0,010 & 0,010 & 0,010 & 0,010 & 0,010 \\
\hline Mistura mineral ${ }^{3}$ (Mineral mix) & 0,050 & 0,050 & 0,050 & 0,050 & 0,050 \\
\hline Mistura vitamínica ${ }^{4}$ (Vitamin mix) & 0,100 & 0,100 & 0,100 & 0,100 & 0,100 \\
\hline $\mathrm{BHT}^{2}$ & 0,010 & 0,010 & 0,010 & 0,010 & 0,010 \\
\hline \multicolumn{6}{|l|}{$\begin{array}{l}\text { Composição calculada } \\
\text { Calculated composition }\end{array}$} \\
\hline PB (CP) (\%) & 20,000 & 20,000 & 20,000 & 20,000 & 20,000 \\
\hline EM (ME) $(\mathrm{kcal} / \mathrm{kg})$ & 2.910 & 2.910 & 2.910 & 2.910 & 2.910 \\
\hline Сa $(\%)$ & 3,200 & 3,200 & 3,200 & 3,200 & 3,200 \\
\hline P disponível (\%) & 0,400 & 0,400 & 0,400 & 0,400 & 0,400 \\
\hline \multicolumn{6}{|l|}{ Available $P$} \\
\hline $\mathrm{Na}(\%)$ & 0,150 & 0,150 & 0,150 & 0,150 & 0,150 \\
\hline \multicolumn{6}{|c|}{ Aminoácidos digestíveis (\%) (Digestible amino acids) } \\
\hline Arg & 1,300 & 1,300 & 1,300 & 1,300 & 1,300 \\
\hline Ile & 0,940 & 0,940 & 0,940 & 0,940 & 0,940 \\
\hline Lys & 1,000 & 1,000 & 1,000 & 1,000 & 1,000 \\
\hline Met & 0,586 & 0,586 & 0,586 & 0,586 & 0,586 \\
\hline Met + Cys & 0,840 & 0,840 & 0,840 & 0,840 & 0,840 \\
\hline Thre & 0,650 & 0,700 & 0,750 & 0,800 & 0,850 \\
\hline $\operatorname{Trp}$ & 0,230 & 0,230 & 0,230 & 0,230 & 0,230 \\
\hline Val & 0,960 & 0,960 & 0,960 & 0,960 & 0,960 \\
\hline
\end{tabular}

1 Avilamicina (Avilamicin).

2 Butil-hidróxi-tolueno (Antioxidante/antioxidant).

${ }^{3}$ Composição/kg de produto (Content/kg of product): Vit. A: 12.000 .000 U.I., Vit $D_{3}: 3.600 .000$ U.I., Vit. E: 3.500 U.I., Vit $B_{1}: 2.500$ mg, Vit $B_{2}$ : 8.000 mg, Vit $B_{6}$ $5.000 \mathrm{mg}$, ácido pantotênico (pantothenic acid): $12.000 \mathrm{mg}$, Biotina (biotin): $200 \mathrm{mg}$, Vit. K: 3.000 mg, ácido fólico (folic acid): 1.500 mg, ácido nicotínico (nicotinic acid): $40.000 \mathrm{mg}$, Vit. $\mathrm{B}_{12}: 20 \mathrm{mg}$, Se: $150 \mathrm{mg}$, Veículo q.s.p.: $1.000 \mathrm{~g}$.

${ }^{4}$ Composição/kg de produto: Mn: 160 g, Fe: 100 g, Zn : 100 g, Cu: 20 g, Co: 2 g, l: 2 g, Excipiente (vehicle) q.s.p.: 1000 g.

por dúzia de ovos ( $k g$ de ração/dz de ovos), componentes dos ovos (gema (g e \%), do albúmen (g e \%) e da casca (g e \%), altura e diâmetro dos ovos (mm) e gravidade específica $\left(\mathrm{g} / \mathrm{cm}^{3}\right)$.

Para o controle do consumo de ração, as sobras e os desperdícios foram pesados e descontados da quantidade de ração pesada para todo o período. Ao final de cada período (21 dias), foi feita a divisão da quantidade de ração consumida pelo número de aves de cada tratamento e pelo número de dias e expresso em gramas de ração consumida/ ave/dia. No caso de aves mortas durante o período, seu consumo médio foi descontado e corrigido, obtendo-se o consumo médio verdadeiro para a unidade experimental em questão.

Os ovos foram coletados diariamente às $8 \mathrm{~h}$. A produção média de ovos em cada período de 21 dias, expressa em porcentagem sobre a média de aves do período (ovo/ave/ dia) e de aves alojadas no início do experimento (ovo/ave alojada), foi obtida computando-se diariamente o número de ovos produzidos, incluindo os quebrados, os trincados e os anormais (ovos com casca mole e sem casca). Também foi calculado o número médio de ovos comercializáveis 
durante o período experimental, retirando-se, neste caso, do total de ovos produzidos, os quebrados, os trincados e os anormais.

Todos os ovos íntegros produzidos em cada repetição foram pesados, em balança de precisão de $0,001 \mathrm{~g}$, durante o $16^{\circ}, 17^{0}$ e $18^{\circ}$ dia de cada período, para se obter o peso médio dos ovos. Após a pesagem, foram escolhidos, aleatoriamente, quatro ovos de cada repetição para quantificação dos componentes dos ovos. Os ovos de cada repetição e de cada dia foram pesados individualmente em balança com precisão de $0,001 \mathrm{~g}$. Após as pesagens dos ovos, os mesmos foram identificados e, posteriormente, quebrados. A gema de cada ovo foi pesada e registrada e a respectiva casca, lavada e seca ao ar, para posterior obtenção de seu peso. $\mathrm{O}$ peso do albúmen foi obtido pela diferença entre o peso do ovo e o peso da gema mais o peso da casca.

O peso médio dos ovos foi multiplicado pelo número total de ovos produzidos no período, obtendo-se a massa total de ovos por período. Esta massa total de ovos foi dividida pelo número total de aves do período e também pelo número de dias do período, sendo finalmente expressa em gramas de ovo/ave/dia.

Foram avaliadas a conversão por dúzia de ovos, expressa pelo consumo total de ração em quilogramas dividido pela dúzia de ovos produzidos ( $\mathrm{kg} / \mathrm{dz}$ ), e a conversão por massa de ovos, que foi obtida pelo consumo de ração em quilogramas dividido pela massa de ovos produzidas em quilogramas ( $\mathrm{kg} / \mathrm{kg})$.

Nos três últimos dias de cada período, todos os ovos íntegros foram coletados e mensurados por intermédio de um paquímetro digital modelo CD - 6"C-B. O diâmetro e a altura dos ovos foram obtidos medindo-se a região equatorial do ovo e a região dos pólos, respectivamente. Após a mensuração, os ovos foram imersos e avaliados em soluções de $\mathrm{NaCl}$ com densidade variando de 1,055 a $1,100 \mathrm{~g} / \mathrm{cm}^{3}$, com intervalos de $0,005 \mathrm{~g} / \mathrm{cm}^{3}$, efetuando-se a medida da densidade ou do peso específico por meio de um densímetro da marca INCOTERM- OM-5565.

Os parâmetros foram submetidos a análises de variância e regressão, de acordo com o programa Sistema para Análises Estatísticas e Genéticas - SAEG (UFV, 2000). As estimativas para a exigência de treonina foram determinadas por meio de análise de regressão linear e quadrática, conforme o melhor ajustamento obtido para cada variável, considerando-se o comportamento biológico das aves.

\section{Resultados e Discussão}

Os níveis de treonina não influenciaram $(\mathrm{P}>0,05)$ os parâmetros descritos na Tabela 2, com exceção do consumo de treonina (CT) que aumentou $(\mathrm{P}<0,01)$ de forma linear, de acordo com a equação $\hat{Y}=-10,6613+245,189 X$; $\mathrm{R}^{2}=0,99$.

A variação observada no CT, em razão do aumento da concentração de treonina na ração, pode ser justificada pelo fato de o consumo de ração (CR) não ter variado $(\mathrm{P}>0,05)$ entre os tratamentos. Portanto, o menor nível de treonina $(0,65 \%)$ foi suficiente para satisfazer as necessidades das codornas, sem comprometer o desempenho.

Os valores obtidos para o CR estão de acordo com os dados obtidos por Albino \& Barreto (2003), que citaram consumo médio diário de ração por ave entre 23 e 26 g, para codornas japonesas na fase adulta. Infere-se que o aumento nos níveis de treonina digestíveis não foram suficientes para produzir desbalanço aminoacídico que resultasse na alteração do perfil plasmático do animal, ativando os mecanismos reguladores do apetite, como descrito por Harper et al. (1970).

Não houve influência $(\mathrm{P}>0,05)$ dos níveis de treonina tanto para produção de ovos/ave/dia como para produção de ovos/ave alojada, portanto, verificou-se que o nível de $0,65 \%$ de treonina foi suficiente para a manutenção da taxa de postura (90,20 e 89,60\%, respectivamente) (Tabela 2). Resultados semelhantes foram obtidos por Allen \& Young (1980) e Shim \& Lee (1993), que reportaram níveis de 0,67 e $0,63 \%$ de treonina nas dietas das codornas, respectivamente, para ótima produção de ovos.

Valores divergentes foram observados em galinhas poedeiras alimentadas com níveis crescentes de treonina $(0,37$ a $0,51 \%)$, que apresentaram melhora na taxa de postura (70,7 a 86,9\%) (Huyghebaert \& Butler, 1991). Este resultado corrobora o obtido por Camps (2001), que concluiu que a suplementação de treonina em uma dieta à base de farelos de trigo e de soja melhorou a produção de ovos de poedeiras comerciais em $4 \%$.

Na literatura revisada, não foram encontrados trabalhos científicos determinando a produção de ovos por codorna alojada. Este é um parâmetro importante a ser observado, uma vez que a mortalidade dessas aves durante o período de postura é elevada quando comparada à mortalidade de galinhas poedeiras. Neste experimento, o índice de mortalidade verificado durante todo o período experimental foi de $6 \%$, correspondendo a uma mortalidade semanal de $0,67 \%$.

Os resultados para produção de ovos comercializáveis revelaram que os níveis de treonina na dieta não influenciaram $(\mathrm{P}>0,05)$ a qualidade dos ovos destinados à comercialização. É possível que, entre outros fatores, a utilização de 3,2\% de cálcio nas dietas experimentais (Barreto et al., 2007), cujo valor ficou acima do recomendado pelo NRC (1994) (2,5\% de cálcio para codornas em postura), 
Tabela 2 - Efeito dos níveis de treonina digestível sobre o desempenho de codornas japonesas em postura Table 2 - Effect of digestible threonine levels on laying Japanese quail performance

\begin{tabular}{|c|c|c|c|c|c|c|c|c|c|}
\hline $\begin{array}{l}\text { Treonina (\%) } \\
\text { Threonine }\end{array}$ & $\begin{array}{l}\text { CR } \\
\text { FI }\end{array}$ & $\begin{array}{c}\mathrm{CT} \\
T I\end{array}$ & $\begin{array}{l}A D \\
Q D\end{array}$ & $\begin{array}{l}\text { AA } \\
L Q\end{array}$ & $\begin{array}{l}\mathrm{OC} \\
C E\end{array}$ & $\begin{array}{l}\text { PO } \\
E W\end{array}$ & $\begin{array}{l}\text { MO } \\
E M\end{array}$ & $\begin{array}{c}\text { CAM } \\
F E M\end{array}$ & $\begin{array}{l}\text { CAD } \\
F D\end{array}$ \\
\hline 0,65 & 22,96 & 149,25 & 90,20 & 89,60 & 99,28 & 11,53 & 10,41 & 2,208 & 0,306 \\
\hline 0,70 & 23,17 & 162,20 & 92,23 & 91,47 & 99,05 & 11,57 & 10,68 & 2,173 & 0,301 \\
\hline 0,75 & 22,59 & 169,40 & 89,78 & 85,90 & 99,34 & 11,32 & 10,17 & 2,225 & 0,302 \\
\hline 0,80 & 23,17 & 185,37 & 92,61 & 91,73 & 99,22 & 11,52 & 10,67 & 2,174 & 0,300 \\
\hline 0,85 & 23,41 & 198,97 & 92,15 & 89,80 & 99,47 & 11,68 & 10,77 & 2,179 & 0,305 \\
\hline Média & 23,06 & 173,04 & 91,39 & 89,70 & 99,27 & 11,52 & 10,54 & 2,192 & 0,303 \\
\hline \multicolumn{10}{|l|}{ Mean } \\
\hline CV (\%) & 5,29 & 5,19 & 5,72 & 7,50 & 0,68 & 2,73 & 7,54 & 3,52 & 3,30 \\
\hline $\mathrm{P}$ & n.s. & $\mathrm{P}<0,01 * *$ & n.s. & n.s. & n.s. & n.s. & n.s. & n.s. & n.s. \\
\hline
\end{tabular}

**Efeito linear pelo teste $F(P<0,01): v=-10,6613+245,189 X ; R^{2}=0,99$ (Linear effect by $F$ test, $\left.P<0.01\right)$.

n.s. - não significativo (not significant).

CR - consumo de ração (g/ave.d), CT - consumo de treonina (mg/ave.d, AD - produção de ovos/ave.d (\%), AA - produção de ovos/ave alojada (\%), OC - produção de ovos comercializáveis (\%), PO - peso do ovo (g), MO - massa de ovos (g), CAM - conversão alimentar por massa de ovos (kg/kg) e CADZ - conversão alimentar/ dúzia ovos ( $\mathrm{kg} / \mathrm{dz})$.

FI - feed intake (g/quail.d), TI - threonine intake (mg/quail.d), QD - egg production/quail.d (\%), LQ - egg production/housed quail (\%), CE - production of commercial eggs (\%), EW - egg weight (g), EM - egg mass (g/quail.d), FEM - feed conversion/egg mass ( $\mathrm{kg} / \mathrm{kg})$, FD - feed conversion/egg dozen $(\mathrm{kg} / \mathrm{dz})$.

tenha melhorado a qualidade da casca, favorecendo a alta porcentagem de ovos comercializáveis observada nesta pesquisa. Idade da ave, temperatura e umidade do galpão, estrutura das gaiolas, tipo de material utilizado na confecção das gaiolas e freqüência de coleta dos ovos também são fatores que podem reduzir a perda de ovos (Hamilton, 1982).

Os resultados de peso de ovo encontrados neste estudo estão coerentes com os obtidos por Ishibashi et al. (1998), que, avaliando os efeitos dos níveis de treonina sobre o desempenho de galinhas poedeiras, em dois experimentos, não observaram efeito de tratamento sobre o peso dos ovos.

Allen \& Young (1980) verificaram piora na massa de ovos (7,10 para 6,19 g, correspondendo à redução de 14,70\%), quando a L-treonina foi retirada da mistura de aminoácidos das rações das codornas.

O valor médio do peso dos ovos obtido nesta pesquisa (11,52 g) encontra-se dentro da faixa de normalidade de peso (9 a 12 g) relatada por Bressan \& Rosa (2002).

Os níveis de treonina também não influenciaram $(\mathrm{P}>0,05)$ a conversão alimentar por massa de ovos e por dúzia de ovos das aves, o que está em concordância com os resultados obtidos por Valério et al. (2000), que, estudando níveis de treonina para duas marcas comerciais de galinhas poedeiras, não encontraram diferenças para a conversão alimentar por massa e por dúzia de ovos. Por outro lado, esses resultados divergem dos obtidos por Huyghebaert \& Butler (1991), que constataram efeito dos níveis de treonina sobre a conversão alimentar por massa e por dúzia de ovos em dietas de galinhas poedeiras. Corroborando estes resultados, Sá (2005), estudando níveis de treonina para galinhas poedeiras, encontrou efeito quadrático para conversão alimentar por dúzia de ovos, sendo que o tratamento com menor teor de treonina apresentou a pior conversão.
Portanto, os resultados encontrados neste experimento, para peso de ovo, massa de ovos e conversão alimentar por massa e por dúzia de ovos evidenciaram que a dieta contendo $0,65 \%$ de treonina atendeu às exigências nutricionais das codornas.

Os níveis de treonina digestível não influenciaram ( $P>0,05$ ) os componentes dos ovos (Tabela 3 ), de modo que o nível de $0,65 \%$ de treonina digestível atendeu de maneira satisfatória cada variável estudada. A gema correspondeu a 3,33 g (28,6\%), o albúmen a 7,37 g $(63,4 \%)$ e a casca a $0,94 \mathrm{~g}$ $(8,0 \%)$ do peso total dos ovos.

Dados da literatura divergentes dos deste experimento, relacionados à qualidade dos ovos, podem ser atribuídos às diferenças entre a estrutura genética, as condições de sanidade, a idade da ave, alimentação e condições ambientais e de manejo (Kul \& Seker, 2004).

Yannakopoulos \& Tserveni-Gousi (1986), avaliando a influência da idade (49 a 154 dias de idade) sobre as características dos ovos de codorna, concluíram que, com o aumento da idade, houve incremento nos pesos de gema, albúmen e casca, atingindo peso médio de 3,93; 6,46 e 0,94 g, respectivamente. Estes valores corresponderam a 34,68\% de gema, 57,02\% de albúmen e 8,30\% de casca.

Kul \& Seker (2004), por sua vez, ministraram uma ração com 17\% de PB e $2.750 \mathrm{kcal}$ de EM/kg para codornas e concluíram que a gema correspondeu a 32,71\%, o albúmen a $59,83 \%$ e a casca a $7,47 \%$, do peso total do ovo. Estes autores relataram que a porcentagem de casca apresenta correlação negativa com o peso do ovo; com o aumento do peso do ovo, há maior acréscimo de gema e albúmen que de casca. Estes resultados concordam com os obtidos por Nordstrom \& Ousterhout (1982), que trabalharam com qualidade dos ovos em galinhas poedeiras comerciais. 
Tabela 3 - Efeito dos níveis de treonina digestível sobre os componentes dos ovos de codornas japonesas em postura Table 3 - Effect of digestible threonine levels on egg components of laying Japanese quails

\begin{tabular}{|c|c|c|c|c|c|c|c|c|c|}
\hline \multirow{3}{*}{$\begin{array}{l}\text { Treonina (\%) } \\
\text { Threonine }\end{array}$} & \multirow{2}{*}{\multicolumn{2}{|c|}{$\begin{array}{l}\mathrm{G} \\
Y\end{array}$}} & \multirow{2}{*}{\multicolumn{2}{|c|}{ A }} & \multirow{2}{*}{\multicolumn{2}{|c|}{$\begin{array}{l}\mathrm{C} \\
S\end{array}$}} & \multirow{3}{*}{$\begin{array}{l}\text { DO } \\
E L\end{array}$} & \multirow{3}{*}{$\begin{array}{l}\text { AO } \\
E W\end{array}$} & \multirow{3}{*}{$\begin{array}{l}\text { GE } \\
S G\end{array}$} \\
\hline & & & & & & & & & \\
\hline & g & $\%$ & g & $\%$ & g & $\%$ & & & \\
\hline 0,70 & 3,31 & 28,29 & 7,44 & 63,64 & 0,94 & 8,07 & 25,21 & 32,16 & 1,074 \\
\hline 0,75 & 3,25 & 28,30 & 7,31 & 63,61 & 0,93 & 8,09 & 25,02 & 31,94 & 1,075 \\
\hline 0,80 & 3,36 & 28,77 & 7,37 & 63,10 & 0,95 & 8,13 & 25,22 & 32,09 & 1,074 \\
\hline \multicolumn{10}{|l|}{ Mean } \\
\hline CV $(\%)^{1}$ & 2,77 & 2,20 & 2,84 & 1,13 & 3,11 & 2,43 & 0,86 & 1,31 & 0,12 \\
\hline$P$ & n.s. & n.s. & n.s. & n.s. & n.s. & n.s. & n.s. & n.s. & n.s. \\
\hline
\end{tabular}

n.s. - não significativo (not significant).

G - gema (g, \%), A - albúmen (g, \%), C - casca (g, \%), DO - diâmetro (mm), AO - altura (mm) do ovo e GE - gravidade específica (g/cm³).

$Y$-yolk (g, \%), A - albumen (g, \%), S- shell $(\mathrm{g}, \%), E L$ - egg length $(\mathrm{mm}), E W$ - width $(\mathrm{mm}), \mathrm{SG}$ - specific gravity $\left(\mathrm{g} / \mathrm{cm}^{3}\right)$.

Nenhum resultado acerca da influência dos níveis de treonina sobre os parâmetros de componentes dos ovos foi encontrado na literatura. Infere-se, portanto, que a ração contendo $0,65 \%$ de treonina foi capaz de fornecer suporte para que a ave não comprometesse a qualidade interna e externa dos ovos.

O diâmetro e a altura do ovo não foram influenciados $(\mathrm{P}>0,05)$ pelos níveis de treonina, conseqüentemente, $\mathrm{o}$ menor nível foi satisfatório para a manutenção da característica externa do ovo. Em valores absolutos, o nível recomendado apresentou redução de $0,87 \%$ no diâmetro e não apresentou diferença na altura do ovo, em relação ao maior nível de inclusão ( $0,85 \%$ de treonina).

O ovo de codorna normalmente possui forma ovalarredondada, com dimensões de aproximadamente $30 \mathrm{~mm}$ de altura e 25 mm de diâmetro (Thompson et al.,1981; Albino \& Barreto, 2003).

Os níveis de treonina não influenciaram $(\mathrm{P}>0,05) \mathrm{o}$ resultado da gravidade específica, indicando que o nível de $0,65 \%$ de treonina não prejudicou a qualidade da casca do ovo.

Observou-se que o valor da gravidade específica ao nível de $0,75 \%$ de treonina elevou-se, de forma nãosignificativa, de 1,074 para $1,075 \mathrm{~g} / \mathrm{cm}^{3}$ em relação aos demais tratamentos, o que se deve ao fato de as aves alimentadas com esta ração terem apresentado menores produção e peso de ovo; com isso, houve maior depósito de casca, acarretando melhora na gravidade específica.

De acordo com todas as variáveis, o nível de 0,65\% de treonina digestível foi suficiente para se alcançarem resultados satisfatórios, tanto no desempenho quanto na qualidade dos ovos de codorna.

\section{Conclusões}

Para proporcionar os melhores resultados de desempenho e de qualidade de ovos, a codorna japonesa não exige mais que $0,65 \%$ de treonina digestível para um consumo de 149,2 mg de treonina digestível/dia ou um consumo diário de 14,34 mg de treonina digestível/g de ovo, correspondendo à relação treonina digestível:lisina digestível de 0,65.

\section{Literatura Citada}

ALBINO, L.F.T.; BARRETO, S.L.T. Codornas: criação de codornas para produção de ovos e carne. Viçosa, MG: Aprenda Fácil, 2003. 289p.

ALLEN, N.K.; YOUNG, R.J. Studies on the amino acid protein requirements of laying japanese quail (Coturnix coturnix japonica). Poultry Science, v.59, n.9, p.2029-2037, 1980.

BARRETO, S.L.T.; PEREIRA, C.A.; UMIGI, R.T. et al. Determinação da exigência nutricional de cálcio de codornas japonesas na fase inicial do ciclo de produção. Revista Brasileira de Zootecnia, v.36, n.1, p.68-78, 2007.

BRESSAN, M.C.; ROSA, F.C. Processamento e industrialização de ovos de codorna. In: SIMPÓSIO INTERNACIONAL DE COTURniCulturA, 2002, Lavras. Anais... Lavras: Universidade Federal de Lavras, 2002. p.85-96.

CAMPS, D.M. Dietas bajas en proteínas con suplementación de treonina y triptofano en la alimentación de ponedoras comerciales. Revista Cubana de Ciencia Avícola, v.25, p.131-136, 2001.

HAMILTON, R.M.G. Methods and factors that affect the measurement of egg shell quality. Poultry Science, v.61, p.2022-2039, 1982 .

HARPER, A.E., BENEVENGA, N.J. WOHLHUETER, R.M. Effects of ingestion of disproportionate amounts of amino acids. Physiological Reviews, v.50, n.3, p.428-558, 1970.

HUYGHEBAERT, G., BUTLER, E.A. Optimun threonine requirements of laying hens. British Poultry Science, v.32, p.575-582, 1991. 
INSTITUT NATIONAL DE LA RECHERCHE AGRONOMIQUE INRA. Alimentação dos animais monogástricos: suínos, coelhos e aves. 2.ed. São Paulo: Roca, 1999. 245p.

ISHIBASHI, T.; OGAWA, T.; ITO, S. et al. Threonine requirements of laying hens. Poultry Science, v.77, p.998-1002, 1998.

KUL, S.; SEKER, I. Phenotypic correlations between some external and internal egg quality traits in the Japanese quail (Coturnix coturnix japonica). International Journal of Poultry Science, v.3, n.6, p.400-405, 2004.

NATIONAL RESEARCH COUNCIL - NRC. Nutrient requirements of poultry. 9.ed. Washington, D.C.: National Academy of Sciences, 1994. 155p.

NORDSTROM, J.O.; OUSTERHOUT, L.E. Estimation of shell weight and shell thickness from egg specific gravity and egg weight. Poultry Science, v.61, p.1991-1995, 1982.

PINTO, R.; DONZELE, J.L.; FERREIRA, A.S. et al. Exigência de metionina mais cistina para codornas japonesas em postura. Revista Brasileira de Zootecnia, v.32, n.5, p.1166-1173, 2003.

ROSTAGNO, H.S.; ALBINO, L.F.T.; DONZELE, J.L. et al. Tabelas brasileiras para aves e suínos: composição de alimentos e exigências nutricionais. Viçosa, MG: Universidade Federal de Viçosa, 2000. 141p.

SÁ, L.M. Exigências nutricionais de lisina, de metionina + cistina e de treonina para galinhas poedeiras no período de 34 a 50 semanas de idade. Viçosa, MG: Universidade Federal de Viçosa, 2005. 79p. Tese (Doutorado em Zootecnia) Universidade Federal de Viçosa, 2005.
SHIM, K.F.; LEE, T.K. Effect of dietary essential amino acids on egg production of laying Japanese quail. Singapore Journal of Primary Industries, v.21, n.2, p.72-75, 1993.

SILVA, M.A.; ALBINO, L.F.T.; ROSTAGNO, H.S. et al. Exigências nutricionais em metionina + cistina para frangos de corte, em função do nível de proteína bruta da ração. Revista Brasileira de Zootecnia, v.29, n.2, p.357-363, 1997.

THOMPSON, B.K.; HAMILTON, R.M.G.; VOISEY, P.W. Relationships among various egg traits relating to shell strength among and within five avian species. Poultry Science, v.60, p.2388-2394, 1981.

UNIVERSIDADE FEDERAL DE VIÇOSA - UFV. SAEG - Sistema para análise estatística e genética. versão 8.1. Viçosa, MG: 2000. 59p. (Manual do usuário)

VALÉRIO, S.R.; SOARES, P.R.; ROSTAGNO, H.S. et al. Determinação da exigência nutricional de treonina para poedeiras leves e semipesadas. Revista Brasileira de Zootecnia, v.29, n.2, p.518-524, 2000.

YANNAKOPOULOS, A.L.; TSERVENI-GOUSI, A.S. Quality characteristics of quail eggs. British Poultry Science, v.27, p.171-176, 1986 